\title{
The Value of Accurate High-Resolution and Spatially Continuous Snow Information to Streamflow Forecasts
}

\author{
Dongyue Li AND DENNIS P. LETTENMAIER \\ Department of Geography, University of California, Los Angeles, Los Angeles, California \\ STEVEN A. MARGULIS \\ Department of Civil and Environmental Engineering, University of California, Los Angeles, Los Angeles, California \\ KONSTANTINOS ANDREADIS \\ Department of Civil and Environmental Engineering, University of Massachusetts Amherst, Amherst, Massachusetts
}

(Manuscript received 6 October 2018, in final form 1 February 2019)

\begin{abstract}
Previous studies have shown limited success in improving streamflow forecasting for snow-dominated watersheds using physically based models, primarily due to the lack of reliable snow water equivalent (SWE) information. Here we use a hindcasting approach to evaluate the potential benefit that a high-resolution, spatiotemporally continuous, and accurate SWE reanalysis product would have on the seasonal streamflow forecast in the snow-dominated Sierra Nevada mountains of California if such an SWE product were available in real time. We tested the efficacy of a physically based ensemble streamflow prediction (ESP) framework when initialized with the reanalysis SWE. We reinitialized the SWE over the Sierra Nevada at the time when the Sierra Nevada had domain-wide annual maximum SWE for each year in 1985-2015, and on 1 February of the driest years within the same period. The early season forecasts on 1 February provide valuable lead time for mitigating the impact of drought. In both experiments, initializing the ESP with the reanalysis SWE reduced the seasonal streamflow forecast errors; compared with existing operational statistical forecasts, the peak-annual SWE insertion and the 1 February SWE insertion reduced the overall root-mean-square error of the seasonal streamflow forecasts by $13 \%$ and $23 \%$, respectively, over the 13 major rivers draining the Sierra Nevada. The benefits of the reanalysis SWE insertion are more pronounced in areas with greater snow accumulation, while the complex snow and runoff-generation processes in low-elevation areas impede the forecasting skill improvement through SWE reinitialization alone.
\end{abstract}

\section{Introduction}

Winter precipitation stored as snow in Sierra Nevada headwater river basins accounts for over three-quarters of California's freshwater supply (Li et al. 2017a). The seasonal snowpack stores water in the winter and releases it as snowmelt in late winter through early summer, alleviating the temporal mismatch between the maximum precipitation during winter and the maximum water demand for urban and agricultural consumption in the summer (Dettinger and Cayan 1995; Vano et al. 2015). In California, accurate and timely seasonal streamflow forecasts help mitigate risks in water management ( $\mathrm{He}$ et al. 2016a) and provide a basis for water allocation

Corresponding author: Dennis P. Lettenmaier, dlettenm@ucla.edu decisions that are resilient to climate variability and drought (Tanaka et al. 2006). Seasonal streamflow forecasts thus help decision-makers facilitate timely coordinated regional responses in order to mitigate impacts of water shortages on agriculture (Scanlon et al. 2012) and associated industries (Scott et al. 2008), as well as other groups with a stake in the shared water resources (e.g., Vicuña et al. 2011). A recent economic analysis of snow water resources indicates the value of the snow in the western United States is on the order of trillions of dollars (Sturm et al. 2017); it is clear that even a marginal increase in streamflow forecast accuracy would have substantial value.

Operational streamflow forecasts in California's major watersheds date to the 1930s (He et al. 2016a). Currently, the California Department of Water Resources 
(DWR) issues streamflow forecasts four times a year (in February, March, April, and May); in each forecast the volumetric runoff in each of the remaining months of a water year (through September) and the seasonal streamflow (i.e., aggregated April-July streamflow volume) are predicted. The DWR streamflow forecasts are based on the regression of historical snow, precipitation, temperature, and streamflow observations in conjunction with the available measurements of these variables up to the forecasting date in the forecasting year (He et al. 2016b). The regression method has evolved since it was first applied almost 100 years ago, but the general method remains at the core of California's operational seasonal streamflow forecasts. An example of the regression commonly used by DWR to estimate the seasonal streamflow for a given basin is of the form

$$
\begin{aligned}
\mathrm{AJRO}= & C_{1}(\mathrm{SNOW})+C_{2}(\mathrm{OMPT})+C_{3}(\mathrm{AJPT}) \\
& +C_{4}(\mathrm{OMRO})+C_{5}(\mathrm{PYRO})+C_{6},
\end{aligned}
$$

where AJRO is the seasonal April-July streamflow volume, SNOW is the snow water equivalent (SWE) index (relative to historical averages), OMPT is the October-March precipitation index, AJPT is the projected April-June precipitation index, OMRO is the measured October-March runoff, PYRO is the prior year's April-July runoff, and the $C_{i}$ parameters are regression coefficients derived by fitting the model to historical observations.

While operational streamflow forecasts like those in Eq. (1) have provided a useful basis for water resources planning, regression methods have several limitations for broader and future applications. First, they rely on in situ SWE data that do not exist in most areas of the globe. Second, where such data is available, the methods assume statistical stationarity of the climatology, an assumption that is increasingly tenuous given ongoing warming (Milly et al. 2008). There is an expectation that streamflow forecast accuracy will decrease as the historical records on which the regression depends become increasingly uninformative of future conditions. For example, the accuracy of regression-based forecasts appears to have peaked in about the 1970s across the West (Pagano et al. 2004); this may well be a result of the widespread warming across the region that is most prominent from the 1970s on, when declines in western U.S. snowpack became well documented (Mote et al. 2018). Third, the operational forecasts issued each month from February to May are based on data from the first day of that month but are not issued until about 2 weeks later (https://cdec.water.ca.gov/snow/bulletin120/index2.html); the 2-week lag potentially affects the value of the forecast for planning purposes (e.g., water allocation). Fourth, the monthly resolution of the regression-based forecasts may not be sufficient to capture large streamflow excursions triggered by extreme runoff events (e.g., rain on snow; Marks et al. 2001) and heat waves during the ablation period (Truffer et al. 2005; Wu et al. 2012) that are projected to occur more frequently as the climate warms (Diffenbaugh et al. 2015; Swain et al. 2018).

In the 1970s, with the advent of conceptual hydrologic models, which incorporated some understanding of watershed dynamics, ensemble streamflow prediction (ESP) was developed (Day 1985). ESP is used by some of the National Weather Service's River Forecast Centers in lieu of regression-based methods. With rapid improvements in computing power, hydrological models have increasingly become spatially distributed (Moradkhani and Sorooshian 2009; Beven 2001), in contrast with the spatially lumped models of the 1970s and earlier (e.g., Crawford 1962; Burnash et al. 1973). They also have progressively moved toward solving full water and energy balances (e.g., Liang et al. 1994; Niu et al. 2011), and many explicitly represent the interaction of vegetation (especially forests; e.g., Dickinson 1984) and snow accumulation and ablation dynamics (e.g., Sun et al. 1999; Vionnet et al. 2012). This progress in model development makes physically based streamflow forecasting attractive, especially in areas without in situ data and/or moving forward where regressions will become unreliable due to the warming climate. For instance, physically based model predictions are more robust to climate change because the physics governing the snow and runoff-generation processes are not statistically derived under the assumption of a stationary climate. Moreover, while regression-based forecasts can only be conducted in areas with sufficient in situ measurements, physically based methods can be applied more broadly, that is, in ungauged or sparsely gauged regions with globally available forcing data (e.g., Rodell et al. 2004; Rienecker et al. 2011).

Despite the benefits described above, physically based streamflow modeling has limitations. A key impediment for physically based models in streamflow forecasting in snow-dominated areas is the lack of reliable snow initial conditions. Multiple studies have found the skill in ensemble-based seasonal streamflow forecasts is derived mainly from initial SWE and soil moisture conditions (Day 1985; Maurer and Lettenmaier 2003; Berg and Mulroy 2006; Mahanama et al. 2008; Koster et al. 2010), but accurate spatially distributed estimates of initial SWE conditions have remained elusive due primarily to the difficulty in accurately simulating the spatial variability of SWE that occurs over a range of spatial scales (Bales et al. 2006; Dozier 2011; Lettenmaier et al. 2015), and to the precipitation 
underestimation in model forcings (mostly as a result of wind catch deficiency in commonly used precipitation gauges and their poor capture of orographic gradients) that in turn propagates to the first-order errors in streamflow forecasts (Adam and Lettenmaier 2003). Another limitation is the difficulty in fully characterizing complex runoff processes (Shi et al. 2008). For example, it has been particularly difficult to accurately estimate streamflow in the snow-rain transition zones (Kormos et al. 2014). There are several reasons that lead to these difficulties in the transition zones: 1) it is hard to accurately quantify the amount of rainfall, snowfall, and snowmelt in these regions due to precipitation and temperature forcing errors (Lundquist et al. 2008), and the different streamflow response to rainfall (Beighley et al. 2005) and snowmelt (Hogan and Blum 2003; McNamara et al. 2005); 2) terrain and geological factors complicate the runoff generating processes and models are often incapable of fully characterizing the streamflow generation process (Ali et al. 2012), especially the subsurface flow (Liu et al. 2013); and 3 ) in the primary flood-generating season, snowpack in the transition zone could go through several melt-refreeze cycles and rain-on-snow (ROS) events; the snowmelt and runoff-generation mechanisms in these processes are often characterized with inadequate accuracy. Therefore, despite the abovementioned increases in model sophistication and computing power, it has been difficult to demonstrate improvements in seasonal streamflow forecast accuracy using physically based models in comparison with regression-based methods (Kumar et al. 2014; Liu et al. 2015). A more comprehensive review of physically based streamflow forecasting is given in Cloke and Pappenberger (2009).

One possible avenue to improve seasonal streamflow forecasts is to improve the forecast initial conditions. Historically, hydrologic initial conditions have been based largely on point measurements (e.g., of SWE), which serve as indicators of conditions over an entire river basin. Absent spatially distributed information, much of the benefit of the higher fidelity spatially distributed hydrologic models cannot be exploited. While work has been done to leverage large-scale continuous SWE products from passive (and active) microwave sensors for streamflow forecasting (e.g., Kumar et al. 2014), the resulting SWE estimates have a number of drawbacks, especially in mountainous areas with deep snowpack. Even though the remote sensing SWE products show better agreement with in situ SWE observations after error correction, the SWE improvement does not necessarily translate to improvement in streamflow estimate (Kumar et al. 2014; Liu et al. 2015). Liu et al. (2015) found that in order to improve streamflow forecasts in snow-dominated watersheds by assimilating SWE data, the key attributes of the SWE data need to include 1) accurate snow quantity in high-elevation areas where gauge measurements are sparse and satellite observations and retrievals tend to be erroneous, and 2) both the SWE data and the hydrologic modeling must have sufficiently high resolution to account for the topographic complexity and its effects on SWE heterogeneity and runoff production. Liu et al. (2015) also point out that the limited success in previous streamflow forecast studies that assimilate SWE observations is primarily due to the snow datasets not simultaneously meeting both requirements. The lack of highquality SWE data has made it difficult even to prove whether better initialization would lead to improved streamflow forecasts; this highlights the need for accurate SWE datasets to improve the streamflow forecast in snow-dominated basins.

Nonetheless, some recent progress has been made in quantifying mountain SWE at high spatial resolutions. For example, the Airborne Snow Observatory (ASO) uses a coupled imaging spectrometer and scanning lidar to measure snow albedo and snow depth at ultrahigh resolution. Combined with distributed snow density modeling, ASO provides the first operational lidar SWE measurement to quantify the volume of water stored in the seasonal snow cover at regional scales (Painter et al. 2016). Li et al. (2017b) developed an ensemble Kalman batch smoother to combine the complementary SWE information from modeling and the enhanced spaceborne passive microwave radiance observations. The resulting high-resolution SWE from the assimilation significantly reduced SWE estimation errors over the rugged Kern River basin in the Sierra Nevada. Another recent novel dataset that has contributed to the quantification of mountain SWE is the Sierra Nevada SWE Reanalysis (SNSR) dataset (Margulis et al. 2016). The SNSR SWE was produced by assimilating Landsatderived fractional snow-covered area observations into a snow model via a particle batch smoother. The smoothing framework exploits the temporal aspects of snow ablation seen in the satellite record over the melt season and how that is coupled to the SWE during the accumulation season and the melt energy fluxes over the ablation season. In other words, the posterior estimate of SWE is consistent (in a Bayesian sense) with both the remotely sensed snow-covered area time series and the modeled snow accumulation and melt and their uncertainties. A key aspect of the SNSR SWE is its spatiotemporal resolution and continuity, long temporal period, and accuracy (more discussion in section 2c). The SNSR SWE has a unique combination of these characteristics that align well with the prototype requirements 
for SWE products used in ensemble seasonal streamflow forecasts. However, as noted above, the SNSR SWE can only be produced at the end of the snow season, that is, it is not available in real time.

Here, we explore the potential value of a high-resolution and spatiotemporally continuous snow characterization for seasonal streamflow forecasts in snow-dominated areas. In particular, we determine the benefit that the SNSR SWE product would have had in this setting had it been available in real time. We do so by performing ESP seasonal hindcasts for 13 major Sierra Nevada river basins for the period of 1985-2015. We use direct insertion to initialize the SWE in a standard ESP system with the SNSR SWE for seasonal streamflow forecasts. This allows for the quantification of how much the initial SWE conditions provided by the reanalysis would have on California's seasonal streamflow forecast accuracy had they been available in real time. It should be noted that our focus is not on developing a new seasonal streamflow forecasting method, but rather on assessing the potential benefit of high-resolution and spatiotemporally continuous SWE data in a physically based seasonal streamflow forecasting context. Therefore, while we initialized the forecast model with SNSR SWE, we did not include reinitialization of soil moisture or runoff in the forecast, nor did we make any attempt to adjust the model physics or to correct the atmospheric forcing (e.g., precipitation and temperature).

\section{Study area, data, and model}

\section{a. Study area}

Our study area consists of the 13 snow-dominated Sierra Nevada river basins shown in Fig. 1 in the headwaters of the Sacramento, San Joaquin, and Tulare River basins. These 13 river basins have a total drainage area of about $75000 \mathrm{~km}^{2}$, with elevations ranging from about 100 to $4280 \mathrm{~m}$. Across the domain there is a general north-south elevation gradient with elevation increasing toward the south. The southern part of the study area is mainly high mountains; the highest point is Mount Whitney $(4280 \mathrm{~m})$ in the Kern River basin at the south end of the domain, whereas the basins in the north mostly have an elevation less than $2400 \mathrm{~m}$. As indicated in Fig. 1, there are stream gauges at the outlet of each basin. At each of these locations, DWR publishes naturalized streamflow, which is the total streamflow that would have resulted had there been no upstream regulation or diversions. DWR also generates streamflow forecasts at these gauge locations based on the regression method described in Eq. (1). Our study area consists mostly of mountainous terrain with deep seasonal snowpack and

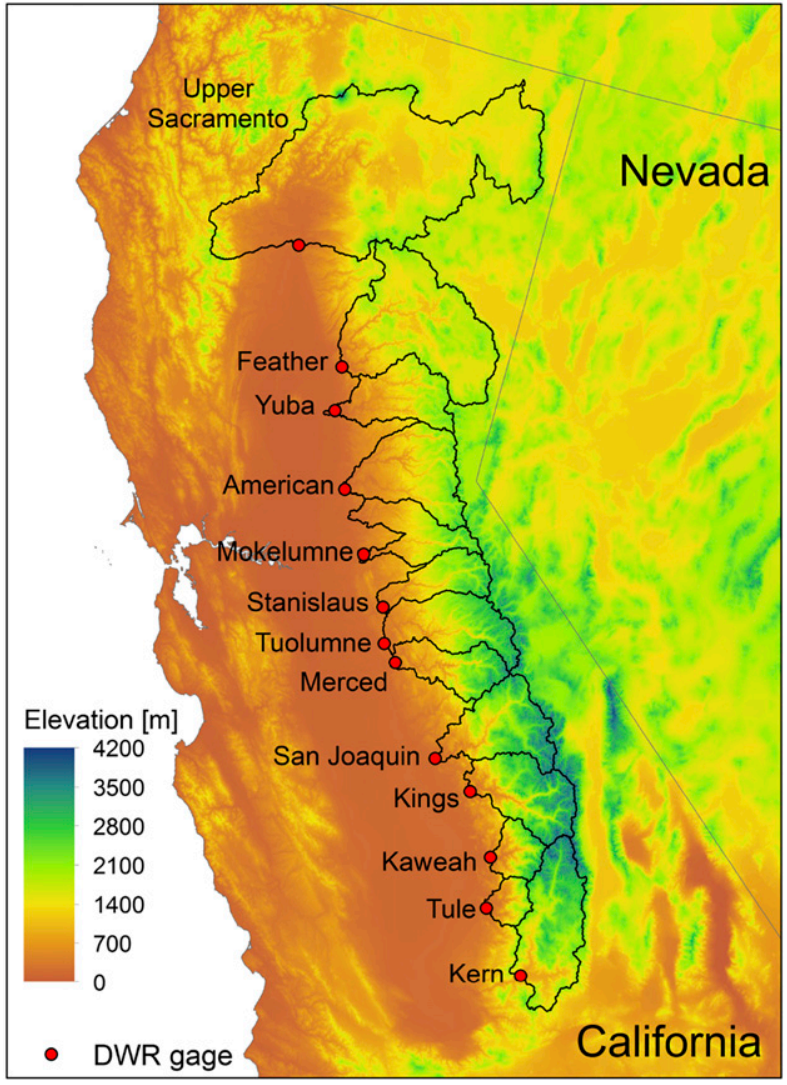

FIG. 1. Map showing the 13 headwater river basins with forecast points (gauges) shown as red dots at which DWR produces seasonal streamflow forecasts and has estimated naturalized streamflows.

relatively thin soils, especially in the southern basins within the domain, so in general the effects of soil moisture on streamflow are expected to be secondary in comparison with snow water storage.

\section{b. Models}

We used the Variable Infiltration Capacity (VIC) hydrology model (Liang et al. 1994) to simulate semidistributed SWE, runoff, and baseflow over the domain. We routed runoff and baseflow to the outlets of the 13 river basins using the VIC routing model (Lohmann et al. 1998). The core of the VIC model has been described in numerous publications, the most relevant of which are Liang et al. (1994) for overall model structure, and Andreadis et al. (2009) for the snow model. In terms of implementation, we used the image mode of VIC version 5 (VIC5; Hamman et al. 2018), which has similar model physics to earlier model versions, but incorporates some functional and structural changes. The most relevant changes to this study include new requirements for forcing data and VIC5's "warm start" feature that facilitates reinitialization of SWE. In earlier 
VIC model versions, the primary model forcing fields are daily precipitation, maximum and minimum temperature, and wind speed from which other variables required by VIC (including downward shortwave and longwave radiation, atmospheric pressure, and vapor pressure) are calculated using the integrated MTCLIM module (Bohn et al. 2013) as a part of the modeling process. In contrast, VIC5 no longer includes MTCLIM and rather directly requires all seven input data fields at subdaily resolution. The VIC5 image mode supports a "break and reinitiate" function that allows the VIC simulation to be stopped at any time step and be "warm started" without the need for spinup, which is realized through a state file that saves the moisture storage and thermal state variables from the time step at which a previous simulation was terminated. We made use of the model's new warmstart capability in our SWE and runoff forecasts.

The VIC snow model simulates the mass and energy balances within a two-layer snowpack, and among the snowpack, vegetation, and the atmosphere via processes including canopy snow interception, drip and release of intercepted snow, and sublimation. Additionally, to characterize the spatial variability of snow and vegetation, each VIC grid cell is subdivided into up to five elevation bands depending on the magnitude of the elevation variation within the grid cell, and each elevation band is further subdivided to a maximum of 12 vegetation zones. The areal fraction of each elevation and vegetation tile is derived from DEM and vegetation data.

We used the VIC routing model (Lohmann et al. 1998) to route runoff from each VIC grid cell to the downstream stream gauges as the model representation of naturalized streamflow. Each grid cell is represented by a node in an eight-direction channel network. The total runoff and baseflow from each grid cell is first convolved with a unit hydrograph that represents the distribution of travel times of water from its points of origin to the channel network. Then, each grid cell's input into the channel network is routed through the channel using the linearized St. Venant's equations. We derived the flow direction and river channel network from the 30-m National Elevation Dataset (NED) DEM in ArcGIS. Prior to routing, we quality-controlled the derived flow directions and manually corrected misclassifications.

The model spatial resolution was $1 / 16^{\circ}$ latitude-longitude $(\sim 6 \mathrm{~km})$ with an hourly temporal resolution for the 31-yr period from 1985 to 2015 . We aggregated hourly model output to daily runoff, baseflow, SWE, soil moisture, evapotranspiration, air temperature and precipitation. The routing model routed runoff and baseflow to the outlet of each basin at the daily time step. We adopted the $1 / 16^{\circ}$ VIC parameterization from Livneh et al. (2013), which is a redevelopment of the $1 / 8^{\circ}$ dataset of Maurer et al. (2002). Some calibration of the model was performed by Maurer et al. (2002); these parameters were essentially interpolated from $1 / 8^{\circ}$ to $1 / 16^{\circ}$ spatial resolution without further calibration by Livneh et al. (2013). In general, the modeled streamflow has a high degree of agreement with the observations [see, e.g., Fig. 3 in Maurer et al. (2002) and Fig. 5 in Livneh et al. (2013)]. These datasets have been applied in numerous streamflow modeling studies (e.g., Lundquist et al. 2015; Mao et al. 2015). No additional model calibration was performed for this study.

\section{c. Data}

The SNSR SWE was produced by assimilating Landsat snow-covered area observations into a snow model via a particle batch smoother (Margulis et al. 2015). It has a high spatial resolution $(90 \mathrm{~m})$ and is available daily over three decades. The spatiotemporally continuous SNSR SWE was developed specifically for areas above the snow line (1500 $\mathrm{m}$ and higher) and has a series of mountain terrain and environmental variables explicitly resolved in each grid cell when generating the data. SNSR SWE has been verified against over 9000 station years of in situ measurements $[R>0.95$ with root-mean-square error (RMSE) ranging from 3 to $13 \mathrm{~cm}$ ].

We forced the VIC model with the hourly NLDAS2 meteorological dataset (Xia et al. 2012). The NLDAS2 dataset has all the meteorological forcing fields needed by VIC5.0, including air temperature, precipitation, downward longwave radiation, downward shortwave radiation, atmospheric pressure, vapor pressure, and wind speed. All these forcing fields are directly included in NLDAS2 except the vapor pressure. However, NLDAS2 includes specific humidity and atmospheric pressure, from which we calculated vapor pressure. We disaggregated the raw $1 / 8^{\circ}$ NLDAS2 forcing data to the $1 / 16^{\circ}$ VIC modeling resolution using an inverse-distance-weighted average of the four nearest NLDAS2 pixels.

We selected NLDAS2 as the meteorological forcing primarily because 1) the SNSR SWE was developed based on NLDAS2; using consistent forcing data allowed us to isolate the effects of SWE improvement on the streamflow forecast accuracy and exclude other factors that would have been introduced by using a different forcing dataset, and 2) NLDAS2 has the high temporal resolution that VIC5 requires (hourly) and near-real-time availability that are attractive for realtime streamflow forecasting. Like many other meteorological forcing data, raw NLDAS2 precipitation has been shown to be negatively biased in mountain regions (Luo et al. 2003; Pan et al. 2003). In the reanalysis 
framework, the effects of the precipitation bias have been implicitly corrected in the SNSR SWE, that is, the reanalysis implicitly corrects the raw NLDAS2 such that the snow depletion matches the remote sensing record. The resulting SNSR SWE product does not contain noticeable bias (details in Margulis et al. 2016). Therefore, in this study, after the SNSR SWE insertion, the SWE conditions are not subject to the first-order biases present in the raw NLDAS2 precipitation data after the SWE direct insertion; this provides an opportunity to directly evaluate how an accurate snow initial condition can mitigate the effects forcing biases at high elevations (which are likely to exist in most of the real-time forcing data) on streamflow forecasting accuracy. The NLDAS2 precipitation bias likely is associated at least in part with gauge undercatch (Pan et al. 2003). While this could be corrected prior to our experiment based on information about gauge types and wind speed measured in our study area, we opted not to make such corrections because 1) wind speed data in NLDAS2 are taken from a coarse-scale atmospheric reanalysis and are interpolated to $1 / 16^{\circ}$ latitude-longitude resolution, and almost certainly do not represent wind speeds at the VIC model scale; 2) gridded datasets by nature incorporate observations at multiple sites, each of which has different local characteristics that affect wind speed, and in some cases, different precipitation gauge types; 3) the in situ measurements needed for bias correction is not available in many other regions, and the bias correction would decrease the universality of the experiments in this study; and 4) in a real-time streamflow forecast scenario, the timeliness requires the forecasting system to be able to rely on raw meteorological measurements that provide real-time but often erroneous or biased precipitation data, and to be able to effectively correct the errors as a part of the forecasting process with the information from other datasets. The application of raw NLDAS2 data provides the opportunity to isolate the extent to which the initial snow condition from the SNSR SWE can reduce the impact of forcing bias in a real-time forecasting scenario.

\section{Methodology}

Our general methodology is to insert the SNSR SWE into the streamflow forecasting framework to replace the modeled (baseline) SWE at the time of forecast initialization. Going forward in time during the forecast period, the streamflow from the forecasting framework therefore reflects the impact of the inserted (SNSR) SWE initial condition. Presumably, the new initial SWE condition immediately reduces the error of the modeled
SWE, allowing us to explore the extent to which the improved SWE affects the accuracy of the seasonal streamflow forecasts.

We carried out two streamflow forecast experiments: a perfect forecast and a standard ESP. In the perfect forecast, we forced the model in the forecast period with the observed historical gridded forcing for that year; the perfection is in the sense that we know the model forcing of the forecasting period in advance, but it does not mean that the forcings are error-free. Therefore, the perfect forecast is an ideal scenario that allows for the assessment of the best possible forecast the system could produce, given the actual realization of the forcing during the forecasting period (Wood et al. 2016). In comparison, ESP produces a more realistic forecasting scenario where the meteorological conditions during the forecast period are unknown, and a forcing ensemble is used to characterize the meteorological dynamics and uncertainty during the forecast period. The perfect forecasting and the ESP used the same forcing data (i.e., raw NLDAS2), however ESP essentially produced retrospective forecasts whereas the perfect forecast is a simulation. Both the perfect forecast and the ESP have an insertion forecast and a baseline forecast; the only difference between the insertion forecast and the baseline forecast is that in the baseline forecast, there is no SNSR SWE reinitialization, so the effect of the initial SWE condition from the SNSR SWE insertion can be evaluated through the comparison with the baseline forecast. With this setting, any improvement in the accuracy of the SNSR insertion streamflow forecasts originates from the improvement in SWE initial conditions.

Our analysis included two streamflow comparisons: 1) baseline forecasts versus insertion forecasts for both the perfect forecasting experiment and ESP experiment, and 2) ESP insertion forecasts versus DWR operational streamflow forecasts (both compared to observed streamflow). The former comparison is analogous to previous studies by Kumar et al. (2014) and Liu et al. (2015), and was done primarily to identify the extent to which the reinitialization of SWE affects streamflow and therefore has the potential to improve streamflow forecasts. The latter comparison with the DWR operational streamflow forecasts allows us to assess the accuracy of a streamflow forecast obtained by reinitializing only the SWE in a physically based forecasting framework against the accuracy of a widely used operational forecast. Note that the objective of this comparison is to use the credible long-term DWR forecasts to gain additional insights into the strength and weakness of the ESP insertion forecasts (in addition to the comparison between insertion 
ESP and baseline ESP) and is not to seek systematic improvement over the operational forecast.

\section{a. Perfect forecast}

For each water year (WY; 1 October and extends until the next 30 September) we ran the VIC model from the beginning of the water year until the time when the SNSR SWE had the Sierra Nevada-wide annual maximum (referred to as the insertion time hereafter; this time varies from year to year, but usually ranges between mid-February and mid-March). On this date, we saved the model states for each elevation band and vegetation zone for that pixel. Next, we carried out the SWE insertion by replacing the VIC modeled SWE with the SNSR SWE for each elevation band and vegetation zone in the VIC grid cell (see the appendix for details). Then, we reinitialized the model with the updated states and performed the forecasts using the forcing data for that year from the insertion time to the end of the water year (this period is referred to as the forecasting period hereafter). All 31 years in the study period follow the same process with the forecasting running continuously throughout the study period. After the forecasting finished for all the $31 \mathrm{WYs}$, we routed the distributed runoff for the time series streamflow for each basin. In the baseline perfect forecast, we follow the same process for each water year, except without the SNSR SWE insertion.

The date of peak SWE can vary by up to a month across the basins in our domain (Margulis et al. 2016). Therefore, carrying out the insertion basin by basin at the peak SWE time of each basin might have improved overall forecast accuracy over the entire domain in comparison with the domain-wide insertion date. However, our experimental setting was to provide a basis for determining whether or not the SWE reinitialization would have benefited streamflow forecasts had the SNSR data been available in real time, rather than developing a new forecasting method for improved forecasting skills. Inserting the SNSR SWE for all basins at the domainwide peak SWE time was deemed adequate for this purpose and is straightforward to implement.

\section{b. Ensemble streamflow prediction}

In the insertion ESP, we ran the VIC model deterministically with the forcing data from the beginning of the WY to the insertion time. We saved the VIC states at this time and replaced the model states with the SNSR SWE. In a realistic (real time) application, for the forecast period from the insertion time to the end of the WY, the meteorological forcings are unknown. Therefore, for the forecasting period, we ran the model with an ensemble consisting of the forcing data from the forecasting period of each year in the study period. All the 31 years in the study period follow the same process with the forecasting running continuously throughout the study period for each ensemble member, resulting in an ensemble of 31 streamflow sequences that collectively reflect the range of past climatic variability and uncertainty. For each WY we calculated the ensemble median across the streamflow ensemble but excluding the ensemble member simulated using the forcing of the forecasted year; this exclusion is to guarantee that no meteorological information from the forecasted year exists in the forecasts. We use median rather than the mean because the median is more resilient to potentially large errors in individual ensemble members caused by model artifacts in the data assimilation.

In addition to the comparison between the insertion ESP and the baseline ESP, we also compared the insertion ESP forecasts with the operational forecasts from DWR. Specifically, we compared the seasonal forecast from the peak-annual SWE insertion ESP with the DWR forecast published at the month in which the peak annual SNSR SWE occurs for all the years. It should be noted that in a real forecasting scenario, we cannot know when the domain-wide peak SWE will occur in advance, therefore, to make the case more general, we also compared the insertion ESP forecasts with the DWR forecasts on the prescribed DWR forecasting dates (i.e., the first day of February to May). In this comparison, we leverage the insertion ESP forecasts made at the insertion time (i.e., when the entire domain has peak annual SWE), and selected the insertion times that are within \pm 4 days to the time when any DWR forecast was made. This selection picked out a subset of 11 years when the insertion times are close to DWR forecasting dates (specifically, 29 March 1985, 28 March 1991, 27 February 1994, 29 January 1997, 3 March 2004, 30 March 2005, 1 March 2007, 27 February 2008, 28 March 2011, 29 January 2013, and 2 April 2014). We used these selected insertion ESP forecast as surrogates of the insertion ESP made on the closest DWR forecasting dates, and compared them with the operational forecasts made at the same time.

Early season streamflow forecasts provide critical lead time for water management, especially in dry years when the value of the forecast is highest, and the forecast accuracy generally is low (Wood and Schaake 2008). After the 2012-16 megadrought in California that resulted in two years of declared emergency status, the significance of accurate early season streamflow forecasts has become increasingly obvious. Therefore, we also carried out an early season seasonal streamflow forecast focusing specifically on drought years. We did so by using direct insertion to assimilate the 1 February SNSR SWE into 
the ESP for the driest years in the study period (defined by having the lowest total annual streamflow) to evaluate how better forecast initialization can affect the forecasts early in dry years. We selected 1 February because 1) it provides several months' lead time for making plans for the peak water consuming season in summer and fall, and 2) the earliest operational DWR forecast of each season is based on 1 February data, which provides a basis to evaluate the early season insertion ESP forecast. In the early season ESP forecast, we followed the same process as in the peak-annual SWE insertion ESP except the insertion was conducted on 1 February. We performed this for the driest $20 \%$ of years in our study period (in ranked order: 2015, 2014, 1987, 2007, 1988, 2013), and compared the seasonal streamflow forecast from the 1 February SWE insertion ESP with that from the February DWR forecast.

\section{Experiment results and discussion}

\section{a. VIC modeling and SWE insertion}

The comparison of the VIC modeled SWE and the SNSR SWE at the insertion time of a dry year (1990) and a wet year (2011), which are broadly representative of other years in those categories, shows that the spatial pattern of the modeled SWE is consistent with that of the SNSR SWE (Fig. 2). In both the dry year and the wet year, the peak SWE generally increases from the north to the south as a result of north-south elevation gradient across the study domain. It is also evident from Fig. 2 that the baseline SWE directly modeled from NLDAS2 forcing is negatively biased in comparison with the SNSR SWE. The SWE difference between the modeled SWE and the SNSR SWE is relatively uniform over the region, with larger differences along the mountain ridges in the Yuba, American, Mokelumne, and Stanislaus watersheds.

The comparison of the SNSR and the VIC modeled SWE volumes as a function of elevation (Fig. 3) shows the elevation-dependent differences. While the modeled SWE is negatively biased at all elevations in both the dry year and the wet year, the most pronounced difference is in the elevation range between 1600 and $2300 \mathrm{~m}$. This elevation range is the main "transitional zone" where precipitation may fall as rain or snow, and rain may fall on previously accumulated snow; the low bias in the modeled SWE in this regions is likely due to joint effects of precipitation biases and air temperature errors. Large rain-on-snow events have the potential to generate hazardous floods, thus it is critical to have accurate SWE in this elevation range especially for future streamflow forecasting where warming will exacerbate these uncertainties.

\section{b. Insertion experiment results versus baseline experiment results}

Using the forecasting results from the Merced River basin as an example, it is clear that in both the perfect forecasting experiment (Fig. 4a) and the ESP experiment (Fig. 4b), the peak-annual SWE reinitialization reduced the baseline streamflow bias, and the resulting seasonal streamflow forecast has a high degree of consistency with the observations. Such improvement is more noticeable when comparing the average monthly baseline streamflow, insertion streamflow, and the observed streamflow at each month; in both the perfect forecasting (Fig. 4c) and the ESP (Fig. 4d) experiments, SWE underestimation translates to a significant negative streamflow bias in the highflow season from April to where SWE is contributing the most to streamflow. In addition, the SWE underestimates lead to the snow in the model melting out earlier than the true condition, and thus exacerbates error in the highflow season baseline streamflow estimate.

The comparison of the aggregated April-July streamflow from the baseline experiment and the insertion experiment for all years at all gauges (Fig. 5) demonstrates an overall improvement in seasonal forecast accuracy from the SWE reinitialization. These results show that in both the perfect forecasts (Fig. 5a) and ESP (Fig. 5b), the baseline predictions are systematically lower than the observed streamflow, and the insertion results better agree with the observations and are more precise. The $r$ value of the baseline perfect streamflow is 0.94 . After the SWE reinitialization it increased to 0.96 in the insertion perfect streamflow. In the ESP experiment, the $r$ value of the perfect ESP streamflow is 0.88 and the SWE reinitialization increased it to 0.93 in the ESP insertion streamflow. All $r$ values are statistically significant at the $95 \%$ confidence level.

To quantify the overall improvement of the seasonal forecast accuracy results from the SWE insertion, we calculated the RMSE and Nash-Sutcliff efficiency (NSE) of the baseline and insertion streamflow from both the perfect forecast and the ESP. We used the normalized information contribution (NIC; Kumar et al. 2014) to quantify the improvement of the SNSR SWE insertion over the baseline streamflow forecast:

$$
\begin{aligned}
\mathrm{NIC}_{\mathrm{RMSE}} & =\frac{\mathrm{RMSE}_{B}-\mathrm{RMSE}_{I}}{\mathrm{RMSE}_{B}}, \\
\mathrm{NIC}_{\mathrm{NSE}} & =\frac{\mathrm{NSE}_{I}-\mathrm{NSE}_{B}}{1-\mathrm{NSE}_{B}},
\end{aligned}
$$

where RMSE ${ }_{B}$ and $\mathrm{RMSE}_{I}$ are the RMSE of the streamflow forecast from the baseline experiment and the insertion experiment, respectively, and $\mathrm{NSE}_{B}$ and $\mathrm{NSE}_{I}$ 

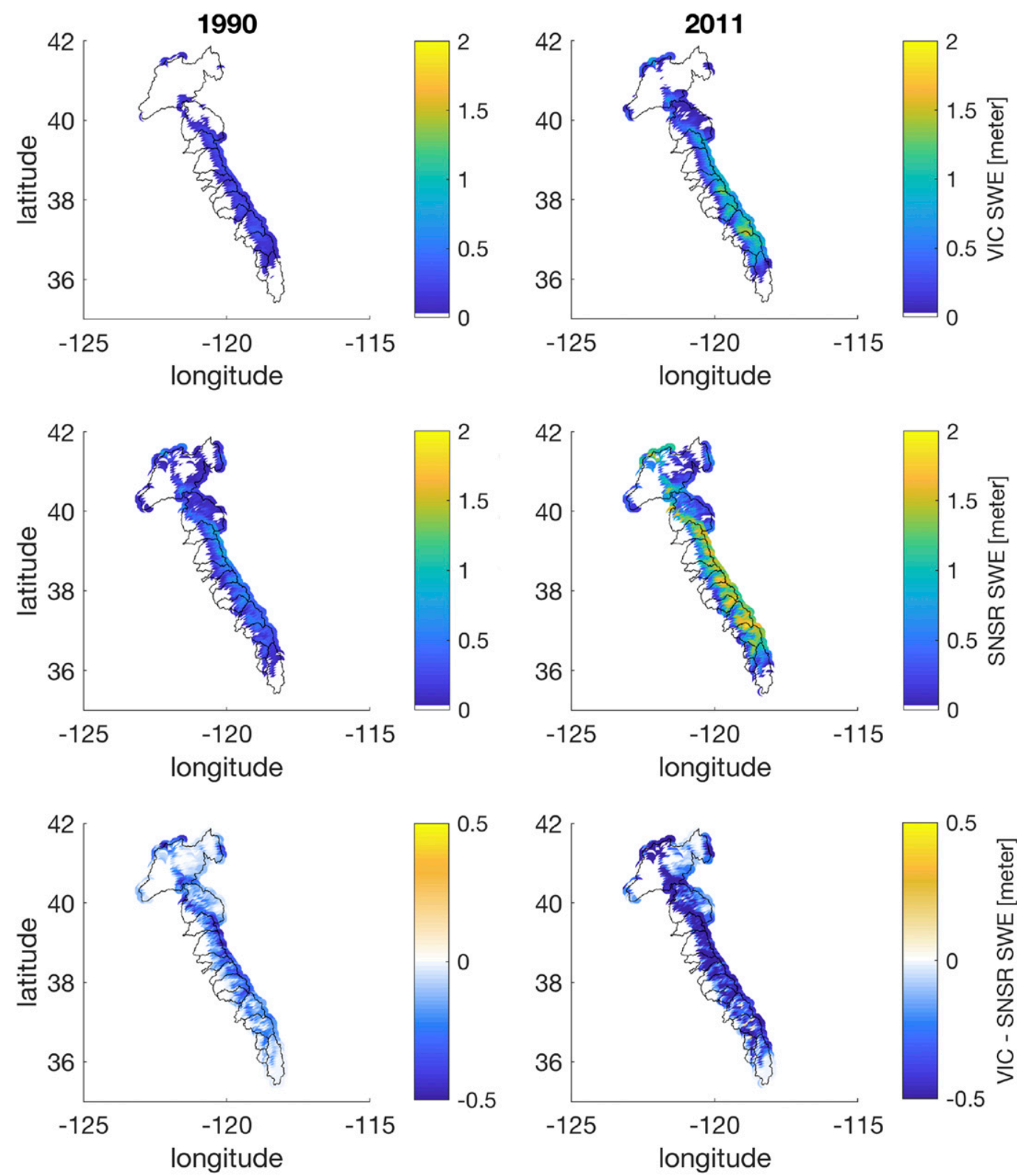

FIG. 2. Comparison of (top) baseline SWE, (middle) SNSR SWE, and (bottom) their difference in (left) a dry year and (right) a wet year.

are the NSE of the streamflow forecast from the baseline experiment and the insertion experiment, respectively Generally, RMSE measures the error magnitude and NSE measures the predictability of the observed streamflow by the forecast. Equations (2) and (3) show that NIC essentially measures the relative RMSE and NSE difference between the baseline forecast and the insertion forecast, and the normalization takes the base magnitude of the streamflow into consideration. Based on its definition, NIC values range from negative infinity to 1 ; for the insertion streamflow and baseline streamflow in both the perfect forecasting and the ESP forecasting, positive NIC indicates the insertion improves the accuracy over the baseline forecast, while negative NIC indicates the insertion degrades with forecasts relative to the baseline. The closer the NIC is to 1, the larger improvement the insertion forecast introduces. In both the perfect forecast and the ESP experiments, the SNSR insertion increases the forecast accuracy over the baseline at all 13 Sierra Nevada basins (Fig. 6). Over the entire domain, the average NIC of RMSE is $34 \%$ and the NIC of NSE is $52 \%$ for the perfect forecasts (Fig. 6a), and 

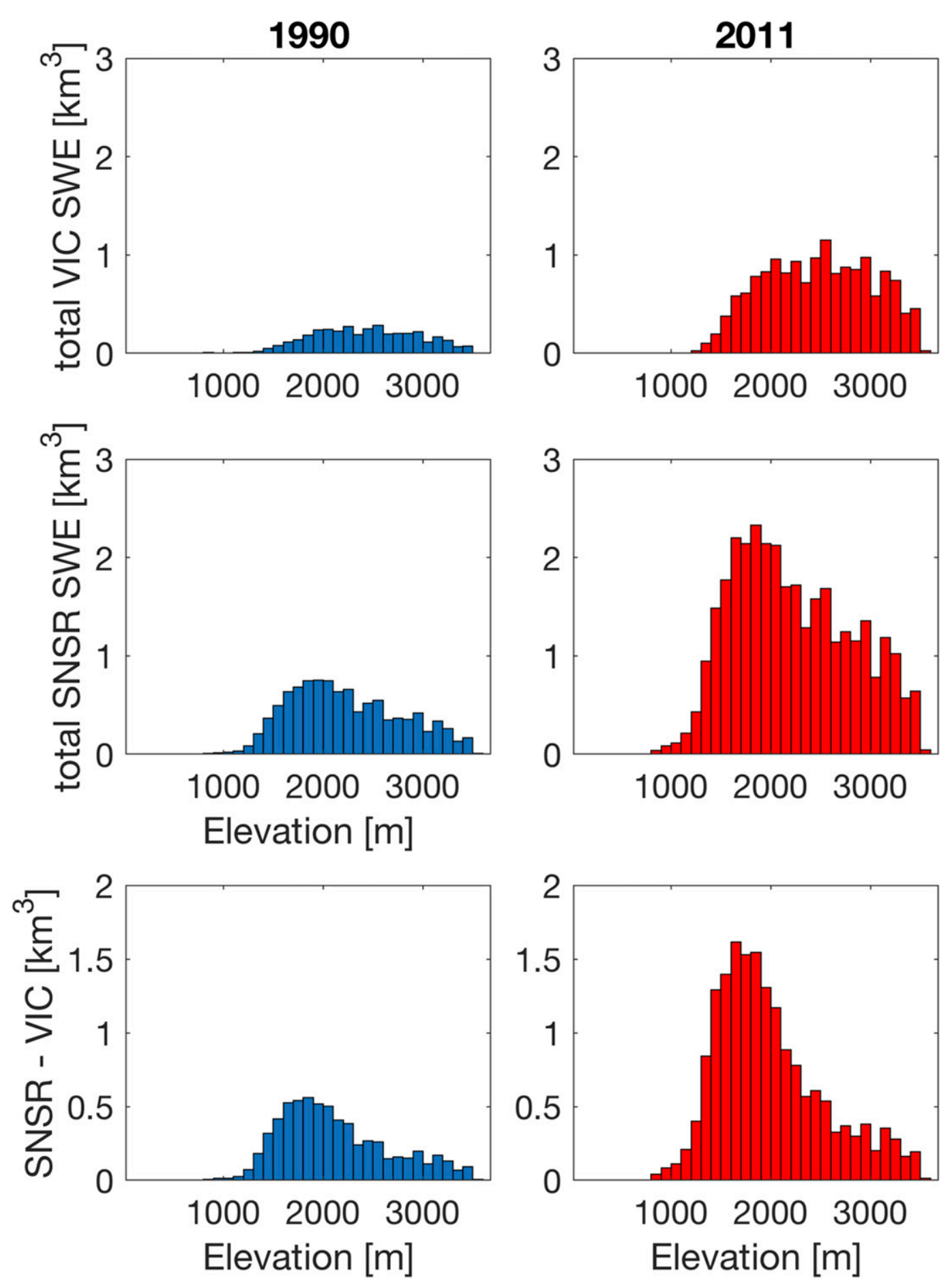

FIG. 3. The elevational distribution of (top) the VIC modeled SWE volume, (middle) the SNSR SWE volume, and (bottom) the volumetric difference between the two as a function of elevation in the (left) dry 1990 and (right) wet 2011.

the average NIC of RMSE is $35 \%$ and the NIC of NSE is $56 \%$ for the ESP forecasts (Fig. 6b), indicating that compared with the baseline forecast, the SNSR SWE reduced the seasonal streamflow forecasting error by over a third and increased the system predictability of the seasonal streamflow by over a half. A $t$ test shows that all the NIC values are statistically significant at $5 \%$ significance level. It should be noted that while the ESP 

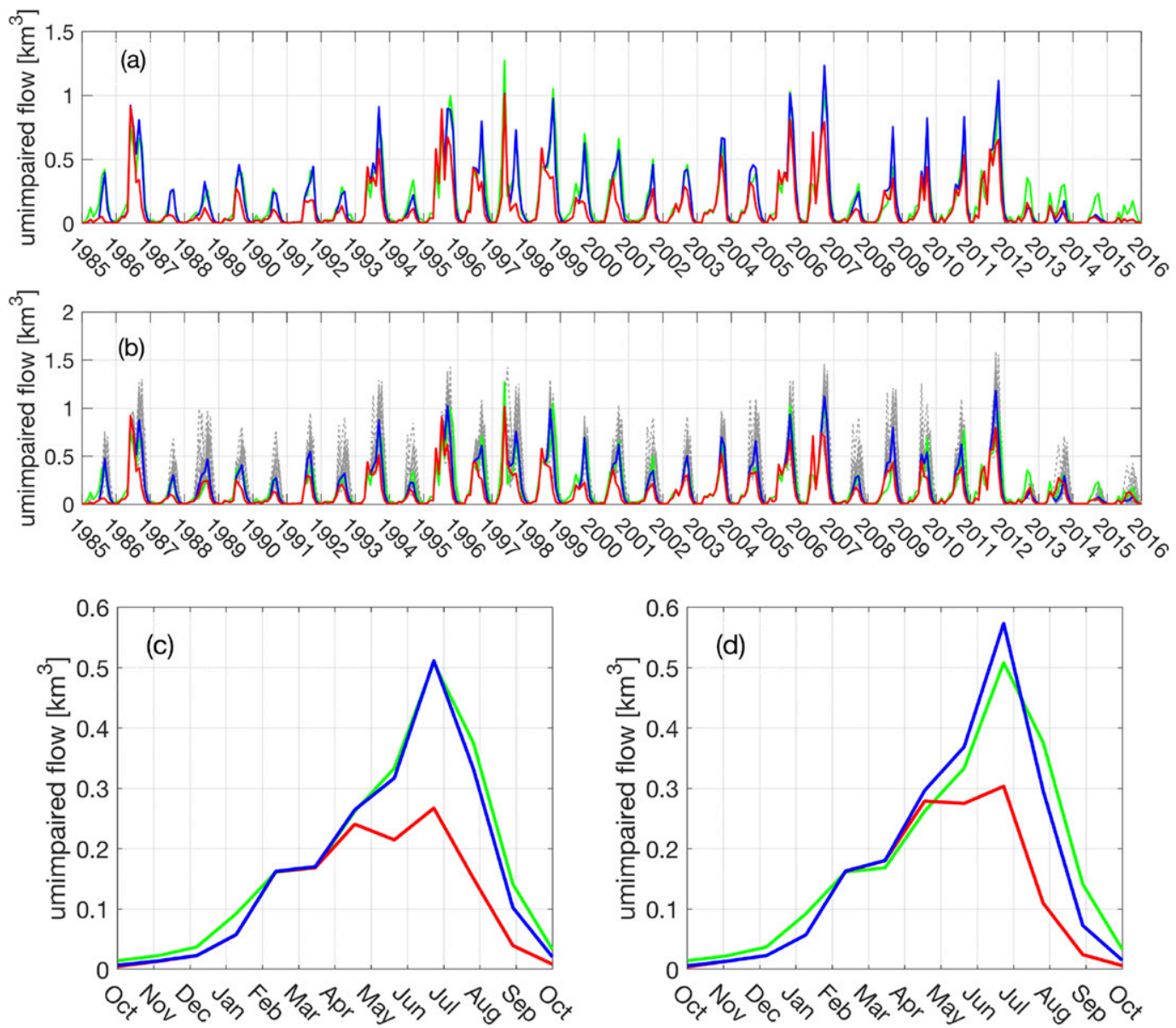

Observed - Baseline - SNSR insertion

FIG. 4. Comparison of the streamflow from the SNSR SWE insertion experiment and the baseline experiment using the Merced River basin experiment results. In all panels, green is the observed streamflow, red is the baseline streamflow, and blue is the SWE insertion streamflow. (a) Comparison of the monthly time series streamflow estimates from the perfect forecasting experiment with the observed streamflow. (b) Comparison of the monthly streamflow estimates from ESP with the observed streamflow. The gray curves represent the ensemble members of the insertion ESP forecast. The average monthly streamflow over the study period from the (c) perfect forecasting and (d) ESP.

experiment has higher NIC values than the perfect forecasts, this does not indicate that the ESP forecast outperforms the perfect forecast. The NIC values for each of the two experiments are relative to their own baseline forecast. The insertion ESP error is in fact larger than the insertion perfect forecast error; compared with the baseline perfect forecast, the insertion ESP reduces the error by $27 \%$ while the insertion perfect forecast reduces $34 \%$.

The magnitude of the seasonal streamflow forecasting accuracy improvement after the SWE insertion varies among the basins (as shown in Fig. 6). We focus on the basins that have NIC values lower than the domain average in Fig. 6 (including the Sacramento, Feather, Yuba, Stanislaus, and Tule), and find that low- and medium-elevation areas occupy a significant portion of the total area of these basins; almost all the areas within these basins are below $2000 \mathrm{~m}$. These low- and mediumelevation areas affect the forecasting in two ways. First, the SNSR SWE is only available in high-elevation areas (above $1500 \mathrm{~m}$ ), so a significant portion of these lowelevation basins does not benefit from the SNSR initialization (e.g., over $80 \%$ of the upper Sacramento basin is not in the reanalysis domain; Margulis et al. (2016, their Fig. 4). As a result, the streamflow generated from these areas is essentially the baseline streamflow that is susceptible to the forcing error, leading to a degradation in the overall streamflow forecasts in these basins. Second, snow in the low-elevation areas could undergo 


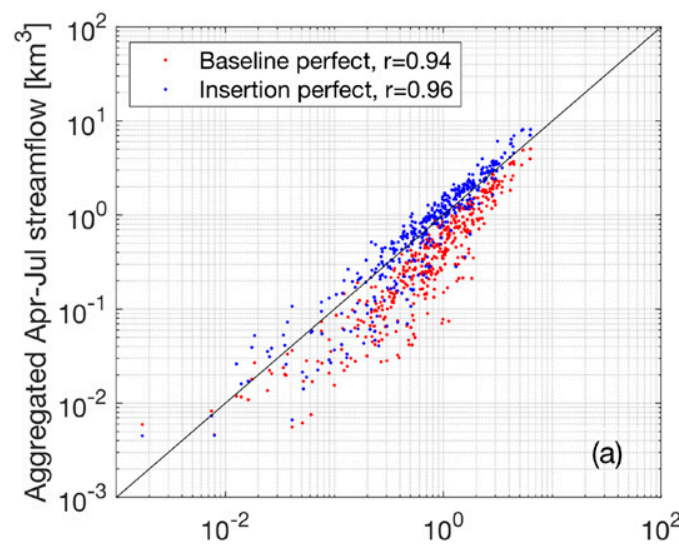

Aggregated Apr-Jul DWR observation $\left[\mathrm{km}^{3}\right]$

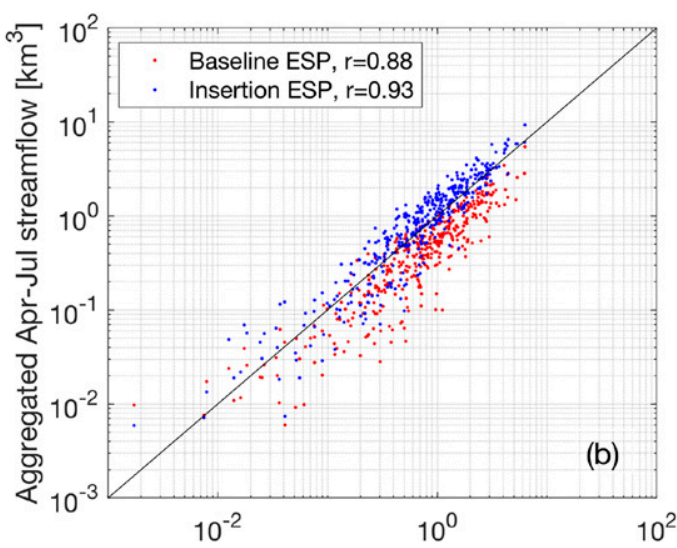

Aggregated Apr-Jul DWR observation $\left[\mathrm{km}^{3}\right]$

FIG. 5. Comparison of the aggregated April-July streamflow from the insertion experiment and the baseline experiment for (a) the perfect forecast and (b) the ESP forecast. Each dot in the scatterplots represents one year's aggregated April-July streamflow at one gauge; the figure compares the data from all 13 basins over all 31 years. All $r$ values are estimated with over $95 \%$ confidence.

multiple rounds of refreeze and rain-on-snow events during the winter, both of which are difficult to characterize even with physically based models (due to high requirement for forcing accuracy and physical snow and runoff process representations), especially if the forcing data contain bias and are uncertain (as in the case herein). These two factors lead to less overall improvement in lower-elevation basins.
Despite the baseline streamflow forecasts being characterized by a negative bias propagated from the precipitation forcing bias, the fact that reinitialization using the SNSR SWE reduces the forecast errors in all the basins (in both the perfect forecasts and ESP) demonstrates the value of accurate peak-annual SWE information to the seasonal streamflow forecast in snow-dominated regions. As discussed in section 2c,
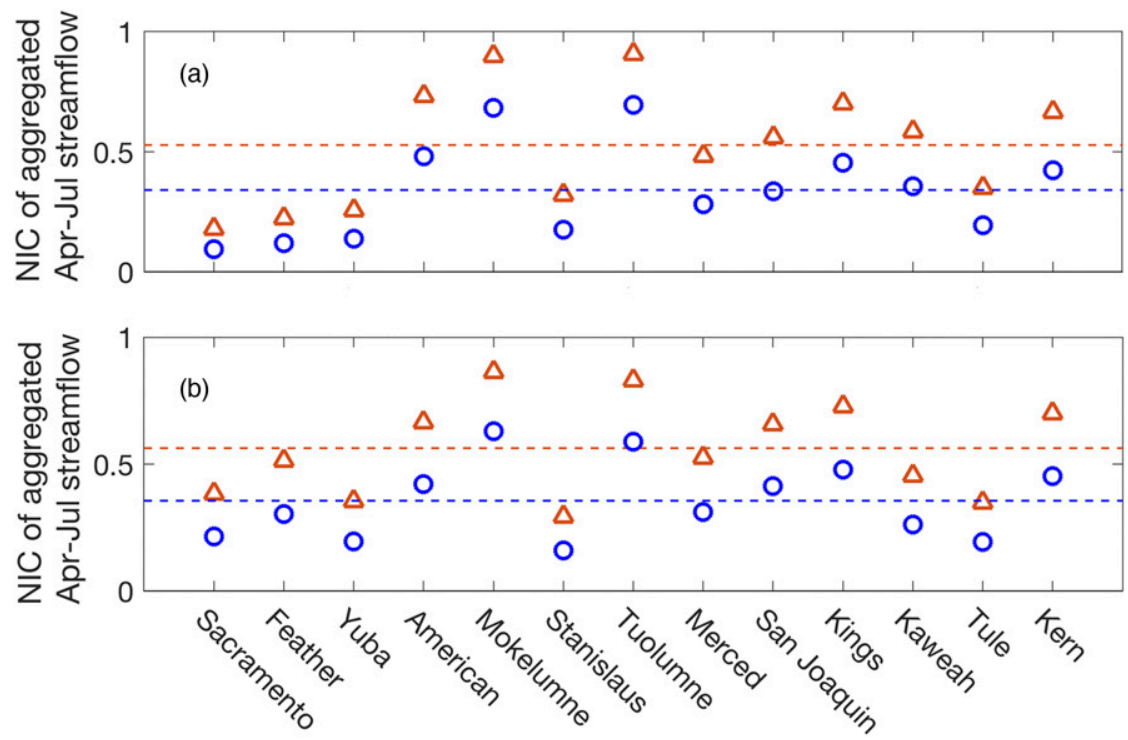

$\triangle$ NIC of NSE - - - mean NIC of NSE O NIC of RMSE - - - mean NIC of RMSE

FIG. 6. The NIC of RMSE (blue circle) and the NIC of NSE (orange triangle) for the aggregated April-July streamflow from (a) the perfect forecast experiment and (b) the ESP experiment at each forecast watershed. In both panels the Sierra Nevada basins are ordered from north (on the left) to south (on the right). 

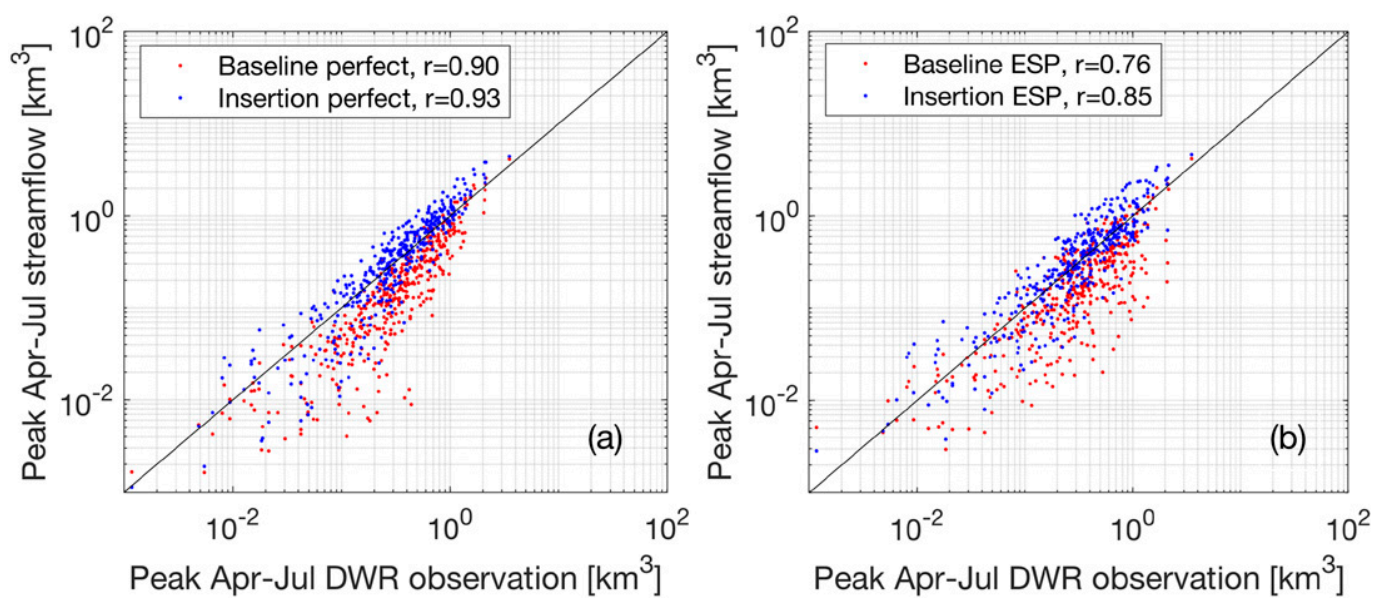

FIG. 7. Comparison of the peak monthly streamflow during April-July from the insertion experiment and the baseline experiment for (a) the perfect forecast and (b) the ESP forecast. Each dot in the scatterplots represents one year's peak monthly streamflow during April-July at one gauge; the figure compares the data from all 13 basins over all 31 years. All $r$ values are estimated with over $95 \%$ confidence.

this is important for the development of physically based real-time streamflow forecasting frameworks in snowdominated regions, where biases are inevitable in model forcings and hence modeling results. In this experiment the reinitialization of SWE is able to effectively correct the modeling errors as a part of the forecasting process. The comparison between the insertion experiment and the baseline experiment shows that a spatially and temporally continuous SWE characterization can effectively prevent the error from propagating to the high-flow season forecast.

The SWE insertion also increased the accuracy of the peak monthly streamflow estimates (i.e., the largest monthly streamflow of a year) in both the perfect forecasting (Fig. 7a) and the ESP (Fig. 7b) case. Similar to the seasonal streamflow forecasts, the peak monthly streamflow from baseline forecast is biased low in both the perfect forecasting and the ESP, and the SNSR SWE reinitialization increases the overall accuracy and precision of both forecasts; the baseline perfect forecast of the peak monthly streamflow has an $r$ value of 0.90 , and it increases to 0.93 after the SWE reinitialization $(p<0.05)$. In the ESP forecasts, the $r$ value of the peak monthly baseline ESP increases from 0.76 to 0.85 after the SWE insertion $(p<0.05)$. The NIC of the peak monthly streamflow magnitude also increases in most of the basins for both the perfect forecasts (Fig. 8b) and the ESP forecasts (Fig. 8b), except for the Sacramento, Feather, and Tule basins. These three basins are dominated by elevations less than $2000 \mathrm{~m}$ (as shown in Fig. 1); the largest runoff events are therefore likely controlled by heavy rainfall events or ROS events, on which the SWE reinitialization has little effects. The overall RMSE of the peak monthly streamflow forecasts was reduced by $15 \%$ in the perfect forecasting and by $24 \%$ in the ESP forecasting, and the overall NSE of the peak monthly streamflow forecasts increased by $11 \%$ in the perfect forecasting and by $31 \%$ in the ESP forecasting.

\section{c. Insertion ESP forecast versus DWR forecast}

Comparison of the aggregated April-July streamflow from the peak-annual SWE insertion ESP and the DWR seasonal forecasts issued at the month when the peak-annual SWE occurs show both forecasts agree with the measurements well (Fig. 9). The $r$ values for the insertion ESP forecasts and the DWR forecasts are 0.93 and 0.86 , respectively. We calculated the RMSE and NSE for both forecasts, as well as the NIC of the insertion forecast over the DWR forecast (Fig. 10). The calculation of the NIC of the insertion ESP forecasts relative to the DWR forecasts followed Eqs. (2) and (3), except the RMSE and NSE of the baseline case were replaced with the RMSE and NSE of the DWR forecasts. As shown in Fig. 10, while both the NIC of RMSE and the NIC of NSE have a mix of positive and negative values across the 13 basins, the average NIC for RMSE is $13 \%$ and the average NIC for NSE is $22 \%$ over the entire domain for the 31-yr period. A $t$ test showed that the mean NIC values are significant based on the basin-wise NIC values at 5\% significance level. The results indicate that the SNSR SWE insertion reduces the overall seasonal forecast errors and increases predictability compared with the DWR forecast at the month when domain-wide maximum SWE occurs (16 years in March, 9 years in April, 6 years in February). 

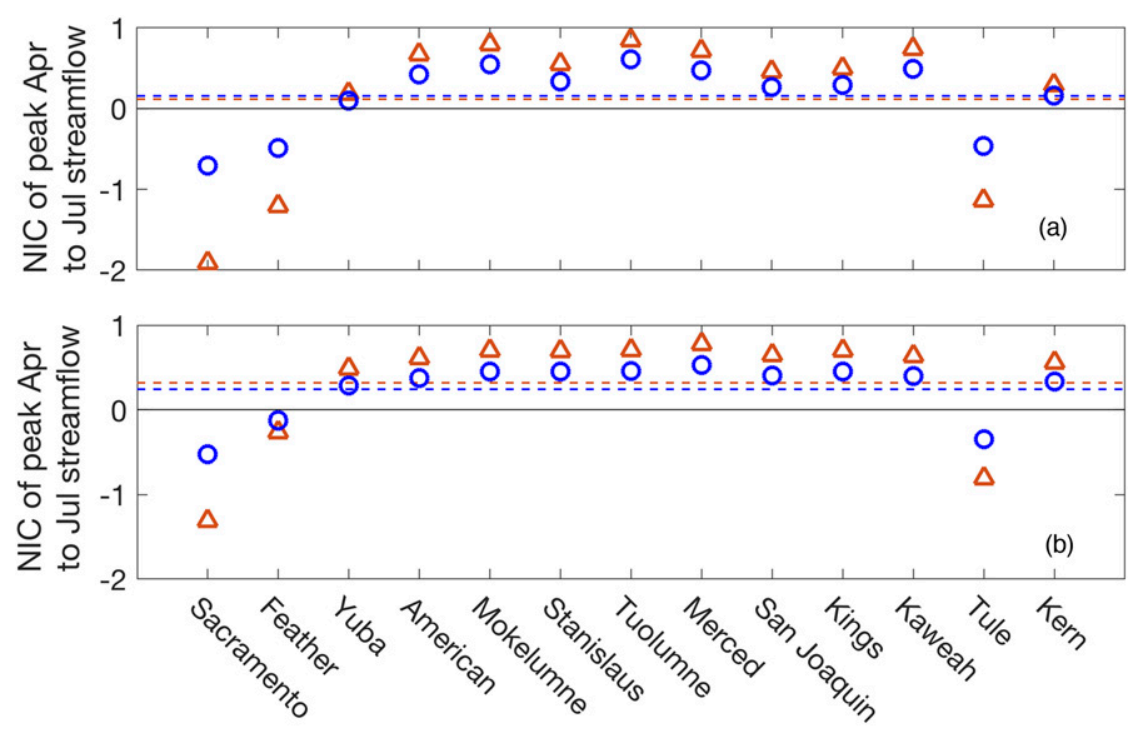

$\triangle \quad$ NIC of NSE - - - mean NIC of NSE O NIC of RMSE - - - mean NIC of RMSE

FIG. 8. The NIC of RMSE (blue circle) and the NIC of NSE (orange triangle) for the peak monthly streamflow during April-July from (a) the perfect forecast experiment and (b) the ESP experiment at each forecast watershed. In both panels the Sierra Nevada basins are ordered from north (on the left) to south (on the right).

In comparing the results of the ESP insertion forecasts to the DWR forecasts (Fig. 10), it is clear that SWE insertion shows less improvement than it did for the baseline ESP, primarily due to the fact that the DWR forecasts do not have the bias that the baseline forecasts do. Specifically, while the insertion ESP outperforms the baseline ESP in all the 13 basins (Fig. 6b), DWR forecasts have slightly better forecasting skills than the insertion ESP forecasts in basins that are dominated by low-elevation areas $(<2000 \mathrm{~m})$. Beyond the lowelevation issues discussed in section $4 \mathrm{~b}$, another likely reason for the difference between the forecasting skill of the insertion ESP in this study versus the DWR forecasts is that the DWR forecast includes measurements of additional hydrologic variables (e.g., streamflow, SWE, and precipitation) up to the forecasting date in the regression, whereas the insertion ESP forecasts were made solely based on the historical climatology (using historical forcing and excluding the forecasted year in calculating ensemble median), without specific information of the hydrologic conditions of the forecasted year in the ESP system. This difference in the forecasting frameworks relates to the varied forecasting skills of the insertion ESP and the DWR forecasts at the low-elevation basins in two ways. First, as discussed, both the physically based forecasts and the statistically based forecasts (e.g., the DWR regression methods) have difficulties in capturing the impacts of complex hydrologic processes (such as ROS) in transition zones needed to accurately predict the streamflow during these events. In this context, the inclusion of the additional measurements in the DWR forecasts helps constrain the errors in the streamflow prediction during these complex events that occur more frequently in low-elevation basins. Second, the hydrologic context in which the runoff is generated is critical

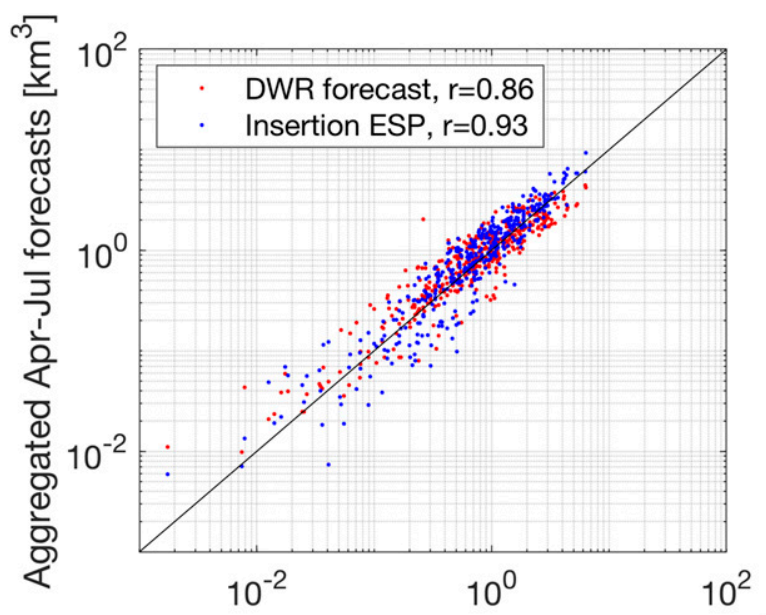

Aggregated Apr-Jul DWR observation $\left[\mathrm{km}^{3}\right]$

FIG. 9. Comparison of the seasonal streamflow forecast from the peak-annual SWE insertion experiment with that from the DWR forecast issued at the peak-SWE month. Each dot in the figure is the aggregated April-July streamflow of a year from one gauge. The figure compares the data from all 13 basins over all 31 years. Both $r$ values are estimated with over $95 \%$ confidence. 


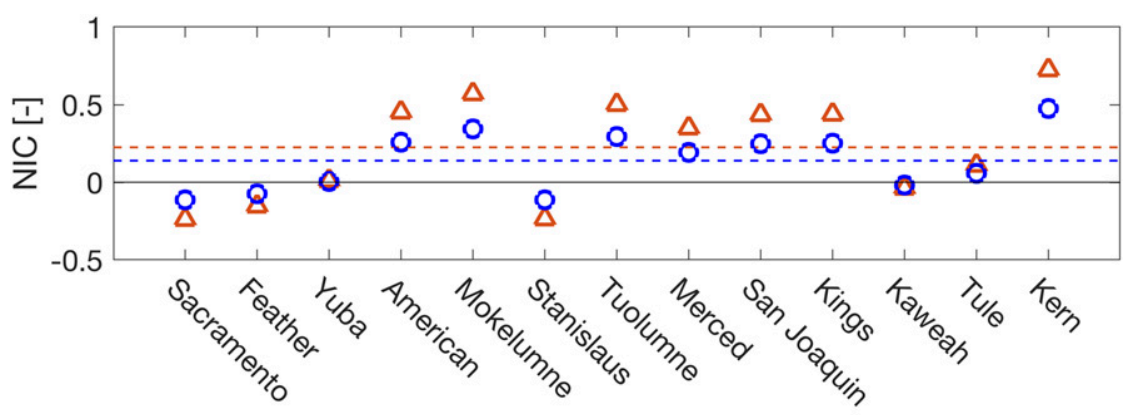

$\triangle$ NIC of NSE --- mean NIC of NSE $\bigcirc$ NIC of RMSE --- mean NIC of RMSE

FIG. 10. The NIC of RMSE (blue circle) and NIC of NSE (orange triangle) of the peakannual SWE insertion forecast over the DWR forecast issued at the peak-SWE month. Basins are ordered from north (on the left) to south (on the right).

to streamflow forecasts (Tetzlaff et al. 2017). The DWR forecasts better address this context with the most recent measurements of the forecasted year's hydrologic information. In comparison, this hydrologic context is absent in the insertion ESP experiment. This highlights the need to include additional constraints on the ESP forecasts (soil moisture, streamflow, etc.) in the future development of operation physically based streamflow forecasts.

We found that comparison between the insertion ESP and the DWR forecasts on the DWR forecasting dates (Fig. 11) had similar results with the comparison between insertion ESP forecast made on the domain-wide peak-SWE time and the DWR forecasts made in that month (Fig. 10). In the comparison made on the DWR forecast times, the overall RMSE of the insertion ESP forecasts were reduced by $12 \%$ and the overall NSE increased by $19 \%$ (Fig. 11). In both comparisons, the SWE reinitialization tends to introduce more improvement to the forecasting skill in the high-elevation snow-dominated basins than to the low-elevation dominated basins. The similarity between the NIC patterns across the basins in these two cases indicate the governing factors for forecasting skill differences are likely the same whether SWE is initialized at domain-side peak SWE timing or at the time nearest DWR forecasts.

\section{d. Early season insertion ESP forecast versus $D W R$ forecast}

In dry years the value of the early season forecast is high, but its accuracy is typically low (Wood and Schaake 2008). We extended our comparison of forecasts for a 1 February SWE insertion ESP with the February DWR seasonal forecast for the driest $20 \%$ of years in our study period (in ranked order: 2015, 2014, 1987, 2007, 1988, 2013). The peak SWE dates in these years were 9 February, 2 April, 27 March, 2 March, 20 January, and 28 January. For each basin, we calculated the seasonal forecast RMSE, NSE, and the NIC of RMSE and NSE in these dry years. The NIC of RMSE results in

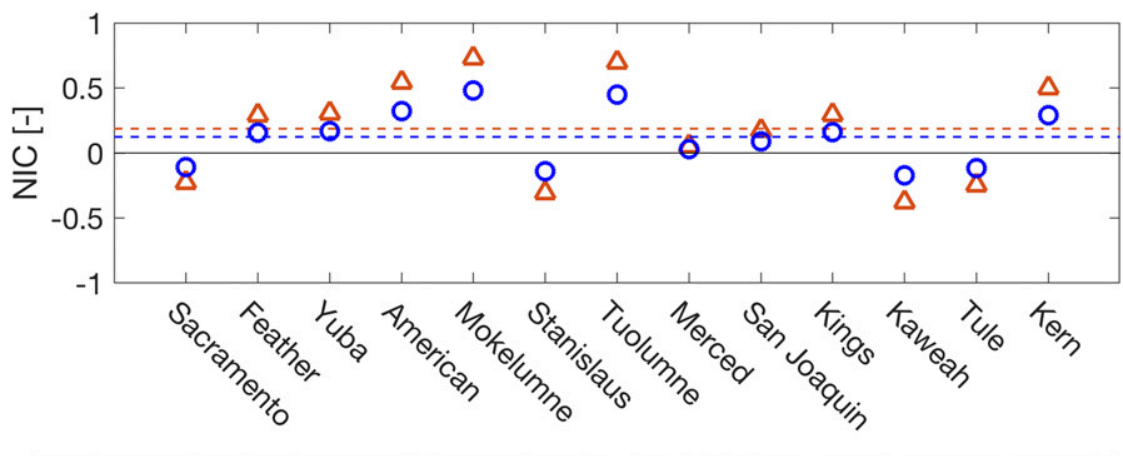

$\triangle$ NIC of NSE - - - mean NIC of NSE O NIC of RMSE - - - mean NIC of RMSE

FIG. 11. The NIC of RMSE (blue circle) and NIC of NSE (orange triangle) of the insertion ESP forecast made on DWR forecasting dates over the DWR forecasts on corresponding dates. Basins are ordered from north (on the left) to south (on the right). 


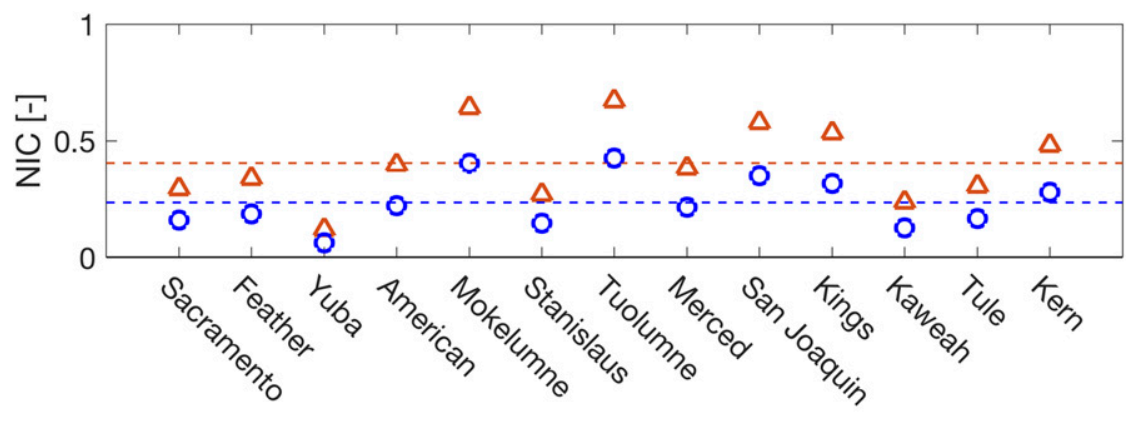

$\triangle \quad$ NIC of NSE - - - mean NIC of NSE $O$ NIC of RMSE - - - mean NIC of RMSE

FIG. 12. The NIC of RMSE (blue circle) and NIC of NSE (orange triangle) of the early season SWE insertion streamflow forecasts over the DWR early season streamflow forecast in the top $20 \%$ driest years. Basins are ordered from north (on the left) to south (on the right).

Fig. 12 shows that the 1 February SNSR SWE insertion increases the seasonal streamflow forecast skill in the extremely dry years in all of the basins. Over the entire domain, the SWE insertion reduces the overall RMSE by $23 \%$ and increases NSE by $40 \%$; both the overall NIC values are statistically significant with $95 \%$ confidence level based on the basin-wise NIC. The distribution of NIC from the 1 February SWE insertion experiment across the basins is similar to that of the peak-annual SWE insertion ESP experiment (for all years), that is, the basins with higher NIC values in the peak-annual SWE insertion experiment also have higher NIC values in the 1 February SWE insertion experiment.

\section{Conclusions}

We explored how a detailed spatial and temporal SWE characterization could benefit a physically based seasonal streamflow forecast in the snow-dominated Sierra Nevada watersheds. We applied a previously validated high-resolution and spatiotemporally continuous SWE reanalysis dataset and a standard ESP framework, and carried out a direct insertion to reinitialize the ESP with the SNSR SWE for seasonal streamflow forecasts. We found the following:

1) Reinitializing the ESP with SNSR SWE reduced the bias associated with the baseline forecasting across all basins, and the resulting streamflow time series has a high degree of agreement with the observed streamflow.

2) Reinitialization of the annual peak SWE increases the accuracy of the seasonal streamflow forecasts relative to operational statistical forecasts over most ( 9 of 13) basins with an overall increase in accuracy of $13 \%$.

3) Early season SWE insertion in the driest $20 \%$ of the years in the 31-yr study period resulted in forecast accuracy improvements at all 13 forecast points, with an overall accuracy increase of $23 \%$.

4) Benefits of the SNSR SWE insertion are more pronounced in basins with more snow accumulation, that is, where streamflow is more snow-dominated (mostly the central and southern Sierra Nevada). Forecasting accuracy improvement in low-elevation areas is more difficult due to the complex snow and runoff-generation processes and the reduced role of snow to the streamflow in those areas.

The results of this study demonstrate that a SWE dataset that has sufficient accuracy in the magnitude and spatial distribution of large-scale snowpack has significant potential for improving streamflow (as demonstrated herein in the Sierra Nevada). Accurate snow information itself (i.e., initial conditions near peak SWE) was shown to be enough to allow physically based forecasts to have similar accuracy with a widely used statistical forecasting approach. Future work could explore the possibility of further improvements by including soil moisture and streamflow measurements as additional constraints in physically based forecasting frameworks. Since the Sierra Nevada has arguably the most complex terrain among the major snow accumulation areas in the western United States, it is reasonable to expect that model reinitialization with an SNSR-like snow dataset could also improve the accuracy of streamflow forecasts in other regions where regression approaches may not be reliable due to lack of in situ data and/or nonstationarity. These results also support the long-term efforts of the hydrologic community to continue to work toward developing near-real-time estimates of SWE (at high spatial and temporal resolution), through a combination remote sensing, reanalysis, machine learning and other methods under consideration, in support of 
the larger goal of improved streamflow forecasts in snowdominated areas of the globe.

Acknowledgments. We thank the three anonymous reviewers and the Editor, Matthew Rodell, whose comments have helped to improve the quality of the manuscript. This study was supported by U.S.-China Clean Energy Research Center for Water-Energy Technologies/California Energy Commission Grant 300-15-006.

\section{APPENDIX}

\section{SNSR SWE Insertion and Reinitialization}

The SNSR SWE insertion was performed at 0000 local time of the day when the domain has its annual maximum SWE in each water year. The SNSR SWE insertion process consists primarily of properly redistributing the SNSR SWE of the 90-m resolution SNSR SWE pixels that fall in each $1 / 16^{\circ}$ VIC grid cell to the grid cell's elevation bands and vegetation zones. As discussed above, in VIC modeling and in the saved VIC state file, each grid cell is divided into a maximum of five elevation bands (band elevation increases from band 1 to band 5), and each elevation band is further divided into twelve vegetation zones (each zone represent one of the eleven vegetation types or the bare soil). The areal ratio of each elevation band to the entire pixel and the areal ratio of each vegetation zone to the elevation band it belongs to are known VIC parameters derived from the DEM and vegetation database. In the insertion, we first aggregated the SNSR SWE from the SNSR pixels locate within each modeling grid cell to calculate the total SWE for each VIC grid cell. Then we proportionally distributed the SWE of a grid cell to its elevation bands and vegetation zones based on their areal ratios. This method preserves both the high-resolution attribute of the reanalysis dataset and the elevational effects on subpixel snow distribution that VIC characterizes.

When replacing the modeled SWE in the VIC state file with the SNSR SWE for a grid cell, there are four snow-availability conditions: 1) both the modeled SWE and the SNSR SWE at the grid cell are nonzero, 2) both the modeled SWE and the SNSR SWE at the grid cell are zero, 3) the modeled SWE is nonzero but the SNSR SWE at this grid cell is zero, and 4) the modeled SWE is zero but the SNSR SWE at this grid cell is nonzero. In all four cases, we replace the modeled SWE in the state file with the SNSR SWE and leave other snow-related variables in the state file unchanged. This is because the VIC model is self-adaptive and automatically adjusts the other snow states based on the new SWE, and the snow states can reach new stability in just a few succeeding steps. Also, if the SWE of a grid cell turns from nonzero to zero after the SWE insertion, the model automatically flags the pixel as "no snow" and sets other snow variables to the default values in no-snow condition (essentially all zeros or N/A) in the immediate next step. If SWE changes from zero to nonzero, the VIC model is able to detect the change after the reinitialization and adjust all the snow state variables to initial conditions using default values. Specifically, among the VIC snow variables, only SWE is calculated prognostically in one time step (with depth and density); all the other variables (e.g., snow temperature, cold content, liquid water content) are calculated diagnostically in the next step, which means that after the SNSR SWE is assigned to a pixel that originally has zero SWE in the state file, the model would use default initial snow density $\left(150 \mathrm{~kg} \mathrm{~m}^{-3}\right)$ to calculate snow depth, and takes these prognostically calculated snow variables to the next step to diagnostically calculate all the other snow variables, and keep this "prognostic SWE estimate in one step and diagnostic estimates of all the other snow variables in the next step" process in the following modeling time steps.

\section{REFERENCES}

Adam, J. C., and D. P. Lettenmaier, 2003: Adjustment of global gridded precipitation for systematic bias. J. Geophys. Res., 108, 4257, https://doi.org/10.1029/2002JD002499.

Ali, G., D. Tetzlaff, C. Soulsby, and J. J. McDonnell, 2012: Topographic, pedologic and climatic interactions influencing streamflow generation at multiple catchment scales. Hydrol. Processes, 26, 3858-3874, https://doi.org/10.1002/hyp.8416.

Andreadis, K. M., P. Storck, and D. P. Lettenmaier, 2009: Modeling snow accumulation and ablation processes in forested environments. Water Resour. Res., 45, W05429, https://doi.org/ 10.1029/2008WR007042.

Bales, R. C., N. P. Molotch, T. H. Painter, M. D. Dettinger, R. Rice, and J. Dozier, 2006: Mountain hydrology of the western United States. Water Resour. Res., 42, W08432, https://doi.org/ 10.1029/2005WR004387.

Beighley, R. E., T. Dunne, and J. M. Melack, 2005: Understanding and modeling basin hydrology: interpreting the hydrogeological signature. Hydrol. Processes, 19, 1333-1353, https:// doi.org/10.1002/hyp.5567.

Berg, A. A., and K. A. Mulroy, 2006: Streamflow predictability in the Saskatchewan/Nelson River basin given macroscale estimates of the initial soil moisture status. Hydrol. Sci., 51, 642654, https://doi.org/10.1623/hysj.51.4.642.

Beven, K. J., 2001: Rainfall-Runoff Modeling: The Primer. Wiley, $488 \mathrm{pp}$

Bohn, T. J., B. Livneh, J. W. Oyler, S. W. Running, B. Nijssen, and D. P. Lettenmaier, 2013: Global evaluation of MTCLIM and related algorithms for forcing of ecological and hydrological models. Agric. For. Meteor., 176, 38-49, https://doi.org/10.1016/ j.agrformet.2013.03.003.

Burnash, R. J. C., R. L. Ferral, and R. A. McGuire, 1973: A generalized streamflow simulation system: Conceptual models for 
digital computers. Joint Federal and State River Forecast Center, U.S. National Weather Service, and California Department of Water Resources Tech. Rep., 204 pp.

Cloke, H. L., and F. Pappenberger, 2009: Ensemble flood forecasting: A review. J. Hydrol., 375, 613-626, https://doi.org/ 10.1016/j.jhydrol.2009.06.005.

Crawford, N. H., 1962: The synthesis of continuous streamflow hydrographs on a digital computer. Dept. of Civil Engineering Tech. Rep. 12, Stanford University, $121 \mathrm{pp}$.

Day, G. N., 1985: Extended streamflow forecasting using NWSRFS. J. Water Resour. Plann. Manage., 111, 157-170, https://doi.org/10.1061/(ASCE)0733-9496(1985)111:2(157).

Dettinger, M. D., and D. R. Cayan, 1995: Large-scale atmospheric forcing of recent trends toward early snowmelt runoff in California. J. Climate, 8, 606-623, https://doi.org/10.1175/15200442(1995)008<0606:LSAFOR > 2.0.CO;2.

Dickinson, R. E., 1984: Modeling evapotranspiration for threedimensional global climate models. Climate Processes and Climate Sensitivity, Geophys. Monogr., Vol. 29, Amer. Geophys. Union, 58-72.

Diffenbaugh, N. S., D. L. Swain, and D. Touma, 2015: Anthropogenic warming has increased drought risk in California. Proc. Natl. Acad. Sci. USA, 112, 3931-3936, https://doi.org/10.1073/ pnas.1422385112.

Dozier, J., 2011: Mountain hydrology, snow color, and the fourth paradigm. Eos, Trans. Amer. Geophys. Union, 92, 373-374, https://doi.org/10.1029/2011EO430001.

Hamman, J. J., B. Nijssen, T. J. Bohn, D. R. Gergel, and Y. Mao, 2018: The Variable Infiltration Capacity model version 5 (VIC-5): Infrastructure improvements for new applications and reproducibility. Geosci. Model Dev., 11, 3481-3496, https:// doi.org/10.5194/gmd-11-3481-2018.

He, M., M. Russo, and M. Anderson, 2016a: Predictability of seasonal streamflow in a changing climate in the Sierra Nevada. Climate, 4, 57, https://doi.org/10.3390/cli4040057.

— forecasts for Sierra Nevada watersheds. Hydrology, 3, 35, https://doi.org/10.3390/hydrology3040035.

Hogan, J. F., and J. D. Blum, 2003: Tracing hydrologic flow paths in a small forested watershed using variations in ${ }^{87} \mathrm{Sr} /{ }^{86} \mathrm{Sr},[\mathrm{Ca}] /$ [Sr],[Ba]/[Sr] and $\delta^{18} \mathrm{O}$. Water Resour. Res., 39, 1282, https:// doi.org/10.1029/2002WR001856.

Kormos, P. R., D. Marks, J. P. McNamara, H. P. Marshall, A. Winstral, and A. N. Flores, 2014: Snow distribution, melt and surface water inputs to the soil in the mountain rain-snow transition zone. J. Hydrol., 519, 190-204, https://doi.org/10.1016/j.jhydrol.2014.06.051.

Koster, R. D., S. P. Mahanama, B. Livneh, D. P. Lettenmaier, and R. H. Reichle, 2010: Skill in streamflow forecasts derived from large-scale estimates of soil moisture and snow. Nat. Geosci., 3, 613-616, https://doi.org/10.1038/ngeo944.

Kumar, S. V., and Coauthors, 2014: Assimilation of remotely sensed soil moisture and snow depth retrievals for drought estimation. J. Hydrometeor., 15, 2446-2469, https://doi.org/ 10.1175/JHM-D-13-0132.1.

Lettenmaier, D. P., D. Alsdorf, J. Dozier, G. J. Huffman, M. Pan, and E. F. Wood, 2015: Inroads of remote sensing into hydrologic science during the WRR era. Water Resour. Res., 51, 7309-7342, https://doi.org/10.1002/2015WR017616.

Li, D., M. L. Wrzesien, M. Durand, J. Adam, and D. P. Lettenmaier, 2017a: How much runoff originates as snow in the western United States, and how will that change in the future? Geophys. Res. Lett., 44, 6163-6172, https://doi.org/10.1002/ 2017 GL073551.
—, M. Durand, and S. A. Margulis, 2017b: Estimating snow water equivalent in a Sierra Nevada watershed via spaceborne radiance data assimilation. Water Resour. Res., 53, 647-671, https://doi.org/10.1002/2016WR018878.

Liang, X., D. P. Lettenmaier, E. F. Wood, and S. J. Burges, 1994: A simple hydrologically based model of land surface water and energy fluxes for general circulation models. J. Geophys. Res., 99, 14 415-14 428, https://doi.org/10.1029/94JD00483.

Liu, F., C. Hunsaker, and R. C. Bales, 2013: Controls of streamflow generation in small catchments across the snow-rain transition in the Southern Sierra Nevada, California. Hydrol. Processes, 27, 1959-1972, https://doi.org/10.1002/hyp.9304.

Liu, Y., C. D. Peters-Lidard, S. V. Kumar, K. R. Arsenault, and D. M. Mocko, 2015: Blending satellite-based snow depth products with in situ observations for streamflow predictions in the Upper Colorado River Basin. Water Resour. Res., 51, 1182-1202, https://doi.org/10.1002/2014WR016606.

Livneh, B., E. A. Rosenberg, C. Lin, B. Nijssen, V. Mishra, K. M. Andreadis, E.P. Maurer, and D.P. Lettenmaier, 2013: A long-term hydrologically based dataset of land surface fluxes and states for the conterminous United States: Update and extensions. J. Climate, 26, 9384-9392, https://doi.org/10.1175/JCLI-D-12-00508.1.

Lohmann, D., E. Raschke, B. Nijssen, and D. P. Lettenmaier, 1998: Regional scale hydrology: I. Formulation of the VIC-2L model coupled to a routing model. Hydrol. Sci. J., 43, 131141, https://doi.org/10.1080/02626669809492107.

Lundquist, J. D., P. J. Neiman, B. Martner, A. B. White, D. J. Gottas, and F. M. Ralph, 2008: Rain versus snow in the Sierra Nevada, California: Comparing Doppler profiling radar and surface observations of melting level. J. Hydrometeor., 9, 194211, https://doi.org/10.1175/2007JHM853.1.

_ M. Hughes, B. Henn, E. D. Gutmann, B. Livneh, J. Dozier, and P. Neiman, 2015: High-elevation precipitation patterns: Using snow measurements to assess daily gridded datasets across the Sierra Nevada, California. J. Hydrometeor., 16, 1773-1792, https://doi.org/10.1175/JHM-D-15-0019.1.

Luo, L., and Coauthors, 2003: Validation of the North American land data assimilation system (NLDAS) retrospective forcing over the southern Great Plains. J. Geophys. Res., 108, 8843, https://doi.org/10.1029/2002JD003246.

Mahanama, S. P., R. D. Koster, R. H. Reichle, and L. Zubair, 2008 The role of soil moisture initialization in subseasonal and seasonal streamflow prediction-A case study in Sri Lanka. Adv. Water Resour., 31, 1333-1343, https://doi.org/10.1016/ j.advwatres.2008.06.004.

Mao, Y., B. Nijssen, and D. P. Lettenmaier, 2015: Is climate change implicated in the 2013-2014 California drought? A hydrologic perspective. Geophys. Res. Lett., 42, 2805-2813, https://doi.org/ 10.1002/2015GL063456.

Margulis, S. A., M. Girotto, G. Cortés, and M. Durand, 2015: A particle batch smoother approach to snow water equivalent estimation. J. Hydrometeor., 16, 1752-1772, https://doi.org/ 10.1175/JHM-D-14-0177.1.

_ Sierra Nevada snow reanalysis (1985-2015). J. Hydrometeor., 17, 1203-1221, https://doi.org/10.1175/JHM-D-15-0177.1.

Marks, D., T. Link, A. Winstral, and D. Garen, 2001: Simulating snowmelt processes during rain-on-snow over a semi-arid mountain basin. Ann. Glaciol., 32, 195-202, https://doi.org/ 10.3189/172756401781819751.

Maurer, E. P., and D. P. Lettenmaier, 2003: Predictability of seasonal runoff in the Mississippi River basin. J. Geophys. Res., 108, 8607, https://doi.org/10.1029/2002JD002555. 
— A. W. Wood, J. C. Adam, D. P. Lettenmaier, and B. Nijssen, 2002: A long-term hydrologically based dataset of land surface fluxes and states for the conterminous United States. J. Climate, 15, 3237-3251, https://doi.org/10.1175/1520-0442(2002)015<3237: ALTHBD $>2.0 . \mathrm{CO} ; 2$.

McNamara, J. P., D. Chandler, M. Seyfried, and S. Achet, 2005: Soil moisture states, lateral flow, and streamflow generation in a semi-arid, snowmelt-driven catchment. Hydrol. Processes, 19, 4023-4038, https://doi.org/10.1002/hyp.5869.

Milly, P. C., J. Betancourt, M. Falkenmark, R. M. Hirsch, Z. W. Kundzewicz, D. P. Lettenmaier, and R. J. Stouffer, 2008: Stationarity is dead: Whither water management? Science, 319, 573-574, https://doi.org/10.1126/science.1151915.

Moradkhani, H., and S. Sorooshian, 2009: General review of rainfall-runoff modeling: model calibration, data assimilation, and uncertainty analysis. Hydrological Modelling and the Water Cycle, Springer, 1-24, https://doi.org/10.1007/978-3-54077843-1_1.

Mote, P. W., S. Li, D. P. Lettenmaier, M. Xiao, and R. Engel, 2018: Dramatic declines in snowpack in the western US. npj Climate Atmos. Sci., 1, 2, https://doi.org/10.1038/s41612-018-0012-1.

Niu, G. Y., and Coauthors, 2011: The community Noah land surface model with multiparameterization options (Noah-MP): 1. Model description and evaluation with local-scale measurements. J. Geophys. Res., 116, D12109, https://doi.org/10.1029/ 2010JD015139.

Pagano, T., D. Garen, and S. Sorooshian, 2004: Evaluation of official western US seasonal water supply outlooks, 1922-2002. J. Hydrometeor., 5, 896-909, https://doi.org/10.1175/15257541(2004)005<0896:EOOWUS > 2.0.CO;2.

Painter, T. H., and Coauthors, 2016: The Airborne Snow Observatory: Fusion of scanning lidar, imaging spectrometer, and physically based modeling for mapping snow water equivalent and snow albedo. Remote Sens. Environ., 184, 139-152, https:// doi.org/10.1016/j.rse.2016.06.018.

Pan, M., and Coauthors, 2003: Snow process modeling in the North American Land Data Assimilation System (NLDAS): 2. Evaluation of model simulated snow water equivalent. J. Geophys. Res., 108, 8850, https://doi.org/10.1029/2003JD003994.

Rienecker, M. M., and Coauthors, 2011: MERRA: NASA's modernera retrospective analysis for research and applications. J. Climate, 24, 3624-3648, https://doi.org/10.1175/JCLI-D-11-00015.1.

Rodell, M., and Coauthors, 2004: The Global Land Data Assimilation System. Bull. Amer. Meteor. Soc., 85, 381-394, https:// doi.org/10.1175/BAMS-85-3-381.

Scanlon, B. R., C. C. Faunt, L. Longuevergne, R. C. Reedy, W. M. Alley, V. L. McGuire, and P. B. McMahon, 2012: Groundwater depletion and sustainability of irrigation in the US High Plains and Central Valley. Proc. Natl. Acad. Sci. USA, 109, 9320-9325, https://doi.org/10.1073/pnas.1200311109.

Scott, D., J. Dawson, and B. Jones, 2008: Climate change vulnerability of the US Northeast winter recreation-tourism sector. Mitig. Adapt. Strategies Global Change, 13, 577-596, https:// doi.org/10.1007/s11027-007-9136-z.

Shi, X., A. W. Wood, and D. P. Lettenmaier, 2008: How essential is hydrologic model calibration to seasonal streamflow forecasting? J. Hydrometeor., 9, 1350-1363, https://doi.org/10.1175/ 2008JHM1001.1.

Sturm, M., M. A. Goldstein, and C. Parr, 2017: Water and life from snow: A trillion dollar science question. Water Resour. Res., 53, 3534-3544, https://doi.org/10.1002/2017WR020840.

Sun, S., J. Jin, and Y. Xue, 1999: A simple snow-atmosphere-soil transfer model. J. Geophys. Res., 104, 19587-19597, https:// doi.org/10.1029/1999JD900305.

Swain, D. L., B. Langenbrunner, J. D. Neelin, and A. Hall, 2018: Increasing precipitation volatility in twenty-first-century California. Nat. Climate Change, 8, 427-433, https://doi.org/10.1038/ s41558-018-0140-y.

Tanaka, S. K., and Coauthors, 2006: Climate warming and water management adaptation for California. Climatic Change, 76, 361-387, https://doi.org/10.1007/s10584-006-9079-5.

Tetzlaff, D., S. K. Carey, J. P. McNamara, H. Laudon, and C. Soulsby, 2017: The essential value of long-term experimental data for hydrology and water management. Water Resour. Res., 53, 2598-2604, https://doi.org/10.1002/2017WR020838.

Truffer, M., W. D. Harrison, and R. S. March, 2005: Record negative glacier balances and low velocities during the 2004 heatwave in Alaska, USA: Implications for the interpretation of observations by Zwally and others in Greenland. J. Glaciol., 51, 663-664, https://doi.org/10.3189/172756505781829016.

Vano, J. A., B. Nijssen, and D. P. Lettenmaier, 2015: Seasonal hydrologic responses to climate change in the Pacific Northwest. Water Resour. Res., 51, 1959-1976, https://doi.org/10.1002/ 2014WR015909.

Vicuña, S., J. A. Dracup, and L. Dale, 2011: Climate change impacts on two high-elevation hydropower systems in California. Climatic Change, 109, 151-169, https://doi.org/10.1007/s10584011-0301-8.

Vionnet, V., E. Brun, S. Morin, A. Boone, S. Faroux, P. Le Moigne, E. Martin, and J.-M. Willemet, 2012: The detailed snowpack scheme Crocus and its implementation in SURFEX v7. 2. Geosci. Model Dev., 5, 773-791, https://doi.org/10.5194/gmd-5773-2012.

Wood, A. W., and J. C. Schaake, 2008: Correcting errors in streamflow forecast ensemble mean and spread. J. Hydrometeor., 9, 132-148, https://doi.org/10.1175/2007JHM862.1.

- T. Topson, A. Newman, L. Brekke, J. Arnold, and M. Clark, 2016: Quantifying streamflow forecast skill elasticity to initial condition and climate prediction skill. J. Hydrometeor., 17, 651-668, https://doi.org/10.1175/JHM-D-14-0213.1.

Wu, Z., Z. Jiang, J. Li, S. Zhong, and L. Wang, 2012: Possible association of the western Tibetan Plateau snow cover with the decadal to interdecadal variations of northern China heatwave frequency. Climate Dyn., 39, 2393-2402, https://doi.org/ 10.1007/s00382-012-1439-4.

Xia, Y., and Coauthors, 2012: Continental-scale water and energy flux analysis and validation for the North American Land Data Assimilation System project phase 2 (NLDAS$2)$ : 1. Intercomparison and application of model products. J. Geophys. Res., 117, D03109, https://doi.org/10.1029/ 2011JD016048. 